\title{
URINARY INCONTINENCE THREE MONTHS AFTER DELIVERY;
} PREVALENCE AND RISK FACTORS

\author{
Dr. Habiba Sharaf Ali, Dr. Nida Anwar Lakhani, Dr. Naila Ghulam Sarwar.
}

ABSTRACT..... Objective: The objective of this study was to investigate prevalence of urinary incontinence at 3 months postpartum and to study how continence status during pregnancy and different factors influence urinary incontinence at 3 months postpartum in primiparous women. Setting: Pregnant women attending routine antenatal clinic at Ziauddin hospital and Kharader general hospital Karachi were recruited to this study. Methods: Urinary incontinence before and during pregnancy was assessed at study enrolment early in the third trimester. Incontinence was re-assessed three months postpartum. Logistic regression analysis was used to assess the role of maternal and obstetric factors in causing postpartum urinary incontinence. Results: Urinary incontinence was reported in 15 women (10.6\% ) out of 141 women, mode of delivery, onset of labor weight of the baby, episiotomy, and the length of the second stage of labor, were not predictive of urinary incontinence after delivery. Adjusted RR for incontinence after spontaneous vaginal delivery compared with elective caesarean section was $2.200(95 \% \mathrm{Cl}$.6-7.28) among women who were continent during pregnancy. Conclusions: Urinary incontinence was prevalent 3 months postpartum. The association between incontinence postpartum mode of delivery, onset of labor, perineal trauma and weight of baby was not statistically significant.

Key words: Urinary incontinence, postpartum, primparity, pakistan.

Article Citation

Ali HS, Lakhani NA, Sarwar NG. Urinary incontinence three months after delivery; prevalence and risk factors. Professional Med J 2013;20(4):530-536.

\section{INTRODUCTION}

Childbirth is a major precursor of urinary incontinence, anal incontinence and pelvic organ prolapse, compromising the quality of life for a large number of women of all ages throughout the world ${ }^{1}$.

Urinary incontinence is defined as the involuntary loss of urine that is objectively demonstrable and is a social or hygienic problem. Most cases can be categorized as either stress, urge, or mixed urinary incontinence. Stress incontinence, the loss of urine during physical activity is the most common type and is caused by a loss of anatomical support of the vesicourethral junction, deficiency of the urethral sphincter, or both. Urge incontinence is the loss of urine associated with a strong desire to void and is caused by over activity of smooth muscles in the bladder wall, a condition known as detrusor instability ${ }^{2}$. Common is stress incontinence which affects $86 \%$ of incontinent women either alone $(50 \%)$ or in conjunction with urge incontinence(36\%). It has been suggested that the cause of stress incontinence is attributable to loss of urethral mobility and abnormal sphincter function and, also low urethral closure pressure is the factor most strongly associated with de novo stress urinary incontinence followed by altered vesical neck mobility ${ }^{3}$.

A series of risk factors seems to be involved in urinary incontinence postpartum and later in life, among which there is growing evidence for the impact of delivery mode $e^{4,5,6}$.

The study of prevalence and risk factors of urinary and fecal incontinence in women is very important to establish preventive strategies. There are different epidemiological studies showing wide variability in the results, probably related to the lack of uniform methodological criteria to evaluate urinary incontinence (UI). The women in this study consists of primigravidas who were continent before pregnancy, as this is the best available clinical model of a pelvis unexposed to known pregnancy related risk factors, and thereby it is the best population to assess the risk of urinary incontinence associated with pregnancy and delivery. Our objective was first, to investigate the 
incidence and prevalence of urinary incontinence 3 months after delivery; second, to study how mode of delivery and other factors may interact with continence status in pregnancy to increase or reduce the risk of urinary incontinence 3 months postpartum ${ }^{6}$.

\section{METHODOLOGY}

Data was taken from primigravidas delivering at Ziauddin hospital and Kharadar general hospital Karachi.Data are based on questionnaires answered during pregnancy and 3 months postpartum. Urinary incontinence before and during pregnancy was assessed at study enrolment early in the third trimester and three months after delivery. Incontinence was reassessed three months postpartum. The questionnaire elicited information on the mode of delivery, onset of labor whether induced or not, duration of second stage of labor, perineal trauma during delivery and the weight of the baby. It also included questions on urinary incontinence whether stress, urge or mixed, on the frequency of symptom. The questionnaire was derived from the terminology of the International Continence Society (ICS)?

The women were asked about current leakage. Incontinence was reported as occurring when coughing/laughing/sneezing, when running/jumping or if they had leakage accompanied by a strong urge to void. Frequency (never, one to four times per month, one to six times per week, once day and more than once a day) and amount (droplets and larger volumes) were registered (never, less than once per week, 1-6 times a week, once a day, more than once a day) of involuntary loss of urine. Women confirming loss of urine in association with coughing, laughing, sneezing, running or jumping were defined as having a stress incontinence component. Women with urgency accompanying loss of urine were defined as having an urge incontinence component. Women who had symptoms of both components are referred to as having mixed urinary incontinence. Logistic regression analysis was used to assess the role of maternal and obstetric factors in causing postpartum urinary incontinence.

Main outcome measures of Urinary incontinence 3 months postpartum was presented as proportions, odds ratios and relative risks (RRs) with $95 \% \mathrm{Cl} . \mathrm{P}$ values less than 0.05 were considered statistically significant.

\section{RESULTS}

A total of 141 primigravid women were included in this study. All women were continent before pregnancy. Mean age was 28 years (range 18-40 years), and mean BMl was $24.5 \mathrm{~kg} / \mathrm{m} 2$ (range $14-54 \mathrm{~kg} / \mathrm{m} 2$ ).

Urinary incontinence was detected in $15(10.8 \%)$ of women after delivery. Among them 62 had normal vaginal delivery, 19 had instrumental deliveries while 60 women had caesarean section. Induction of labor was done in $46 \%$ of patients, perineal trauma was reported in $57.4 \%$ of patients either in the form of episiotomy or injury involving anal sphincter. The duration of labor was under one hour in $52.5 \%$, more than one hour in $18 \%$ of women.

The urinary characteristics of study population is shown in Table-I showing the type of incontinence stress, urge or mixed, frequency and amount of urinary incontinence three month after delivery. The table also shows dysparunia and other sexual dysfunction among these women. Stress incontinence was the most common type of incontinence among women 3 months postpartum $(n=8 ; 53.3 \%)$. Only $6.6 \%$ of woman had urinary leakage more than one per day and only one woman leaked larger amounts of urine.

No significant difference was detected in the mode of delivery whether women delivered by caesarean section or had vaginal delivery, in the onset of labour whether induced or not, perineal trauma and the baby's birth weight among women who were continent during 
pregnancy and three months after delivery.

\section{DISCUSSION}

This is a prospective study of 140 women highlighting the magnitude of the problem of urinary incontinence three months after delivery in primiparous women who were continent during pregnancy.

Incidence of urinary incontinence postpartum among primiparous women who were continent both before and during pregnancy varies from 5 to $21 \% 6,89$. The frequency of urinary incontinence is low in our study as compared to the studies done in other countries, also only a fraction of the women reported frequent leakage of urine or leaking larger amounts.

A series of risk factors seems to be involved in urinary incontinence postpartum and later in life, among which there is growing evidence for the impact of delivery mode $\mathrm{d}^{4,510}$. Onset of labour, perineal trauma and fetal weight.

The impact of delivery mode on the development of urinary incontinence has been much debated. It is uncertain whether women who deliver by cesarean section have an increased risk of urinary incontinence as compared with nulliparous women and whether women who deliver vaginally have an even higher risk.

Guri Rortveit ${ }^{11}$ in EPINCONT study which involves a large number of women showed prevalence of 15.9 percent in the Cesarean-section group and 21.0 percent in the vaginal-delivery group. It has been said that the risk of urinary incontinence is higher among women who have had cesarean sections than among nulliparous women and is even higher among women who have had vaginal deliveries.

A prospective cohort study by Van Brumman ${ }^{12}$ showed stress incontinence more prevalent in a group delivered vaginally than by caesarean section.
McKinnie $V^{13}$ in a study involving multicentre studied the prevalence of urinary and fecal incontinence after vaginal delivery and caesarean section and found an increase risk of developing $\mathrm{UI}$ following pregnancy but no difference in the development of urinary incontinence among vaginal and caesarean section group concluding that Cesarean section does not decrease the risk of urinary or fecal incontinence compared to pregnancy with a vaginal delivery.

A study done by Charlotte Chaliha16 also showed, that elective caesarean section may protect against the development of urinary incontinence, but the risk of faecal incontinence and other urinary symptoms including urge incontinence may not be reduced.

Episiotomy was introduced in part to protect the pelvic floor and prevent urinary incontinence ${ }^{1}$.

But our and others' work $^{8,24}$ do not show a significant association between episiotomy and urinary incontinence.

Forceps delivery has sometimes been suggested to be responsible for stress incontinence. A study by Meyer ${ }^{16}$ however found no significant difference in stress incontinence incidence between women with spontaneous delivery and forceps delivery.

A similar result was obtained by Foldspang et a $1^{17}$. Who were unable to demonstrate a significant relationship between stress urinary incontinence and forceps delivery in a large cohort of 4345 women.

Studies done by Wilson ${ }^{18}$ and Farrell ${ }^{19}$ also found no increased risk with forceps deliveries. Vacuum extraction also did not significantly increase risk. We could also not find any significant risk with these instrumental deliveries.

Allen has shown damage to the Pelvic floor during labor ${ }^{20}$ and described neurophysiologic changes in 
association with a long second stage and larger babies. However, in our study and studies done by others ${ }^{20,21,22}$. Found that birth weight and the length of the second stage did not contribute to postpartum urinary incontinence.

To our knowledge no study showing UI prevalence in Pakistani women has to date been reported and this is first of this kind seeing the affect of different factors on the postpartum incontinence. The study has several limitations. One limitation is small number of patients thus not truly showing the prevalence and influence of various risk factors on urinary incontinence in our population. There is need to do study on large number of patients, also there is need to follow patients for longer duration.

\section{CONCLUSION}

The study of prevalence and risk factors of urinary incontinence in women is very important to establish preventive strategies. The prevalence of urinary incontinence was $10.6 \%$ among the primigravida who were continent during pregnancy. Stress IC was more prevalent than urge incontinence. No significant risk factors were identified.

\section{Copyright@ 23 Apr, 2013.}

\begin{tabular}{|c|c|c|}
\hline Urinary incontinence 3 months after delivery & n & $\%$ \\
\hline Yes & 15 & 10.6 \\
\hline No & 126 & 89.4 \\
\hline \multicolumn{3}{|l|}{ Type of incontinence 3 months after delivery } \\
\hline Stress & 8 & 53.3 \\
\hline Urge & 4 & 26.6 \\
\hline Both & 3 & 20 \\
\hline \multicolumn{3}{|c|}{ Frequency of Urinary incontinence 3 months after delivery } \\
\hline Never & 126 & 89.4 \\
\hline 1-4 times/month & 3 & 2.1 \\
\hline $1-6$ times $/ \mathrm{wk}$ & 11 & 7.8 \\
\hline Once a day & 1 & 0.7 \\
\hline More than once a day & 0 & 0 \\
\hline \multicolumn{3}{|c|}{ Amount of urinary incontinence 3 months after delivery } \\
\hline Dreplets & 14 & 9.9 \\
\hline Large amount & 1 & 0.7 \\
\hline None & 126 & 89.4 \\
\hline \multicolumn{3}{|l|}{ Other problem $(n=20)$} \\
\hline Dysparunia & 7 & 85.0 \\
\hline Sexual Dysfunction & 13 & 15.0 \\
\hline \multicolumn{3}{|l|}{ Medical consultant $(n=20)$} \\
\hline Yes & 6 & 30 \\
\hline No & 14 & 70 \\
\hline
\end{tabular}




\begin{tabular}{|c|c|c|c|c|c|c|}
\hline \multirow{3}{*}{$\begin{array}{l}\text { Characteristic } \\
\text { Mod of delivery }\end{array}$} & \multicolumn{4}{|c|}{ Urinary Incontinence } & \multicolumn{2}{|c|}{ Chi square test } \\
\hline & \multicolumn{2}{|c|}{ No } & \multicolumn{2}{|c|}{ Yes } & \multirow{2}{*}{$\begin{array}{c}\text { Statistic } \\
1.733^{\mathrm{a}}\end{array}$} & \multirow{2}{*}{$\begin{array}{r}\text { P-value } \\
0.188\end{array}$} \\
\hline & & & & & & \\
\hline LSCS & 56 & $93.3 \%$ & 4 & $6.7 \%$ & & \\
\hline SVD/NVD/FVD & 70 & $86.4 \%$ & 11 & $13.6 \%$ & & \\
\hline Onset of Labour & & & & & $2.858^{\mathrm{a}}$ & 0.091 \\
\hline Not induced & 71 & $84.6 \%$ & 5 & $15.4 \%$ & & \\
\hline Induced & 55 & $93.4 \%$ & 10 & $6.6 \%$ & & \\
\hline Perineal Trauma & & & & & $1.733^{\mathrm{a}}$ & 0.188 \\
\hline Intact & 56 & $93.3 \%$ & 4 & $6.7 \%$ & & \\
\hline $\begin{array}{l}\text { Epiziotomy/ Anal } \\
\text { Sphincter Involved }\end{array}$ & 70 & $86.4 \%$ & 11 & $13.6 \%$ & & \\
\hline Baby Weight & & & & & $1.733^{\mathrm{a}}$ & 0.188 \\
\hline$>3.5$ & 9 & $93.3 \%$ & 1 & $6.7 \%$ & & \\
\hline$<$ equal 3.5 & 117 & $86.4 \%$ & 14 & $13.6 \%$ & & \\
\hline
\end{tabular}

\begin{tabular}{|c|c|c|c|c|c|c|c|c|}
\hline & \multirow{2}{*}{ B } & \multirow{2}{*}{ S.E. } & \multirow{2}{*}{ Wald } & \multirow{2}{*}{ df } & \multirow{2}{*}{ P-value } & \multirow{2}{*}{$\mathbf{O R}$} & \multicolumn{2}{|c|}{ 95.\% C.I } \\
\hline & & & & & & & Lower & Upper \\
\hline \multicolumn{9}{|l|}{ Mod of delivery } \\
\hline LSCS & & & & & & $\mathrm{R}$ & & \\
\hline SVD / VVD / FVD & .788 & .611 & 1.666 & 1 & .197 & 2.200 & .665 & 7.283 \\
\hline \multicolumn{9}{|l|}{ Perineal Trauma } \\
\hline Intact & & & & & & $\mathrm{R}$ & & \\
\hline Episiotomy & .788 & .611 & 1.666 & 1 & .197 & 2.200 & .665 & 7.283 \\
\hline \multicolumn{9}{|l|}{ Baby Weight } \\
\hline$>3.5$ & & & & & & $\mathrm{R}$ & & \\
\hline$<$ equal 3.5 & .788 & 1.091 & .005 & 1 & .946 & 1.077 & .127 & 9.144 \\
\hline \multicolumn{9}{|l|}{ Onset of Labour } \\
\hline Not Induced & & & & & & $\mathrm{R}$ & & \\
\hline Induced & .948 & .576 & 2.708 & 1 & .100 & 2.582 & .834 & 7.991 \\
\hline OR; Odd Ratio, C I; Confi & val, ${ }^{\circledR}$ & eference & jroup & & & & & \\
\hline
\end{tabular}




\section{REFERENCES}

1. Erica Eason, Michel Labrecque, Sylvie Marcoux and Myrto Mondor. Effects of carrying a pregnancy and of method of delivery on urinary incontinence: a prospective cohort study. BMC Pregnancy and Childbirth 2004, 4:4.

2. Joao L. Amaro, Carlos A. Macharelli, Hamilto Yamamoto, Paulo R. Kawano, Carlos R. Padovani, Aparecido D. Agostinho. Prevalence and Risk Factors for Urinary and Fecal Incontinence in Brazilian Women 2009; 35(5): 592-598.

3. John 0. L. DeLancey, MD,, Janis M. Miller, RN, PhD, CAN. Vaginal birth and de novo stress incontinence: Relative contributions of urethral dysfunction and mobility. Obstet Gynecol. 2007; 110(2 Pt 1): 354-362.

4. Burgio KL, Zyczynski H, Locher JL, Richter HE, Redden $\mathrm{DT}$, Wright KC. Urinary incontinence in the 12-month postpartum period. Obstet Gynecol 2003; 102:1291.

5. Rortveit G, Daltveit AK, Hannestad YS, Hunskaar S. Urinary incontinence after vaginal delivery or cesarean section. N Engl J Med 2003; 348:900-7.

6. SL -Wesnes S, Hunskaar S, Bo K, Rortveit G. The effect of urinary incontinence status during pregnancy and delivery mode on incontinence postpartum. A cohort study. BJOG 2009; 116:700-707.

7. Abrams $P$, Cardozo L, Fall M, Griffiths D, Rosier $P$, Ulmsten $U$, et al. The standardisation of terminology of lower urinary tract function: report from the Standardisation Sub-committee of the International Continence Society. Neurourol Urodyn 2002; 21:167-78.

8. Viktrup L, Lose G, Rolff M, Barfoed K: The symptom of stress incontinence caused by pregnancy or delivery in primiparas. Obstet Gynecol 1992;79:945-94.

9. Glazener CM, Herbison GP, MacArthur C, Lancashire R, McGee MA, Grant AM, et al. New postnatal urinary incontinence: obstetric and other risk factors in primiparae. BJOG 2006; 113:208-17.

10. Kuh D, Cardozo L, Hardy R. Urinary incontinence in middle aged women: childhood enuresis and other lifetime risk factors in a British prospective cohort. J
Epidemiol Community Health 1999; 53:453.

11. Guri Rortveit, M.D,Anne Kjersti Daltveit, Ph.D,Yngvild S. Hannestad, M.D and Steinar Hunskaar, M.D. Urinary Incontinence after Vaginal Delivery or Caesarean Section. N Engl J Med 2003; 348:900-7.

12. Van Brummen HJ, Bruinse HW, Van de Pol G, Heintz AP, Van der Vaart $\mathrm{CH}$. Bothersome lower urinary tract symptoms 1 year after first delivery: prevalence and the effect of childbirth. BJU Int. 2006 Jul; 98(1):89-95.

13. Vikki McKinnie, MD,Steven E. Swift, MD, Wang, MSPH, Patrick Woodman, DO, Amy O'Boyle, $M D$, The effect of pregnancy and mode of delivery on the prevalence of urinary and fecal incontinence. American Journal of Obstetrics \& Gynecology 2005; 193: 512-517.

14. Margie Kahn, MD. The effect of pregnancy and mode of delivery on the prevalence of urinary and fecal incontinence. American Journal of Obstetrics and Gynecology 2005; 193:512-8.

15. Charlotte Chaliha, Alex Digesu, Anna Hutchings, Marco Soligo, Vik Khullar. Caesarean section is protective against stress urinary incontinence: an analysis of women with multiple deliveries. BJOG: an International Journal of Obstetrics and Gynecology 2004; 111: 754-755

16. S. Meyer, P. Hohlfeld, C. Achtari, A. Russolo, P. De Grandi. Birth trauma: short and long term effects of forceps delivery compared with spontaneous delivery on various pelvic floor parameters. British Journal of Obstetrics and Gynecology 2000; 107: 1360-1365.

17. Foldspang A, Hvidman A, Mommsen S, Foldspang A, Hvidman A, Mommsen S. et al. Risk of postpartum urinary incontinence associated with pregnancy and mode of delivery. Acta Obstat Gynecol Scand. 2004; 83:923-7.

18. Wilson PD, Herbison RM, Herbison GP: Obstetric practice and the prevalence of urinary incontinence three months after delivery. Br J Obstetric Gynaecol 1996; 103:154-161.

19. Farrell SA, Allen VM, Baskett TF: Part Wilson PD, 
Herbison RM, Herbison GP: Obstetric practice and the prevalence of urinary incontinence three months after delivery. Br J Obstet Gynaecol 1996, 103:154161

20. AllenRE, HokerGL,Smith ARB. Pelvic floor damage and childbirth; a neurophysiological study. $\mathrm{Br} J$ Obstet Gynaecol.1990;97:770-9.

21. Milsom I, Altman D, Lapitan MC, Nelson R, Sillén U, Thom D: Epidemiology of urinary (UI) and faecal (FI) incontinence and pelvic organ prolapse (POP). In: Abrams P,Cardozo L, Khoury S, Wein A (eds). Incontinence, 4th edn.Committee 1. Paris, France: Health Publication Ltd. 2009:37-111.
22 Martins G, Soler ZA, Cordeiro JA, Amaro JL, Moore KN: Prevalence and risk factors for urinary incontinence in healthy pregnant Brazilian women. Int Urogynecol J. 2010;21:1271-7.

23. Simone Botelho, Joseane Marques da Silva, Paulo Palma, Viviane Herrmann, Cassio Riccetto Can the delivery method influence lower urinary tract symptoms triggered by the first pregnancy? Int Braz J Urol. 2012; 38: 267-76.

24. Sleep J, Grant A: West Berkshire perlneal management trial: three year follow-up. Br Med $\mathrm{J}$ $1987,295: 749-751$.

\section{AUTHOR(S):}

1. DR. HABIBA SHARAF ALI MBBS, MRCOG, Msc, FRCOG

Professor Obstetrics \& Gynecology

Ziauddin University Karachi.

2. DR. NIDA ANWAR LAKHANI

Postgraduate Trainee Obstet \& Gynae

Ziauddin University Karachi.

3. DR. NAILA GHULAM SARWAR

Postgraduate Trainee Obstet \& Gynae

Ziauddin University Karachi.
Correspondence Address:

Dr. Habiba Sharaf Ali

MBBS, MRCOG, Msc, FRCOG

Professor Obstetrics \& Gynecology

Ziauddin University Karachi.

Sf3, Block 1B, Sea view Apartment, Defense Phase V, Karachi. rabel5@yahoo.com

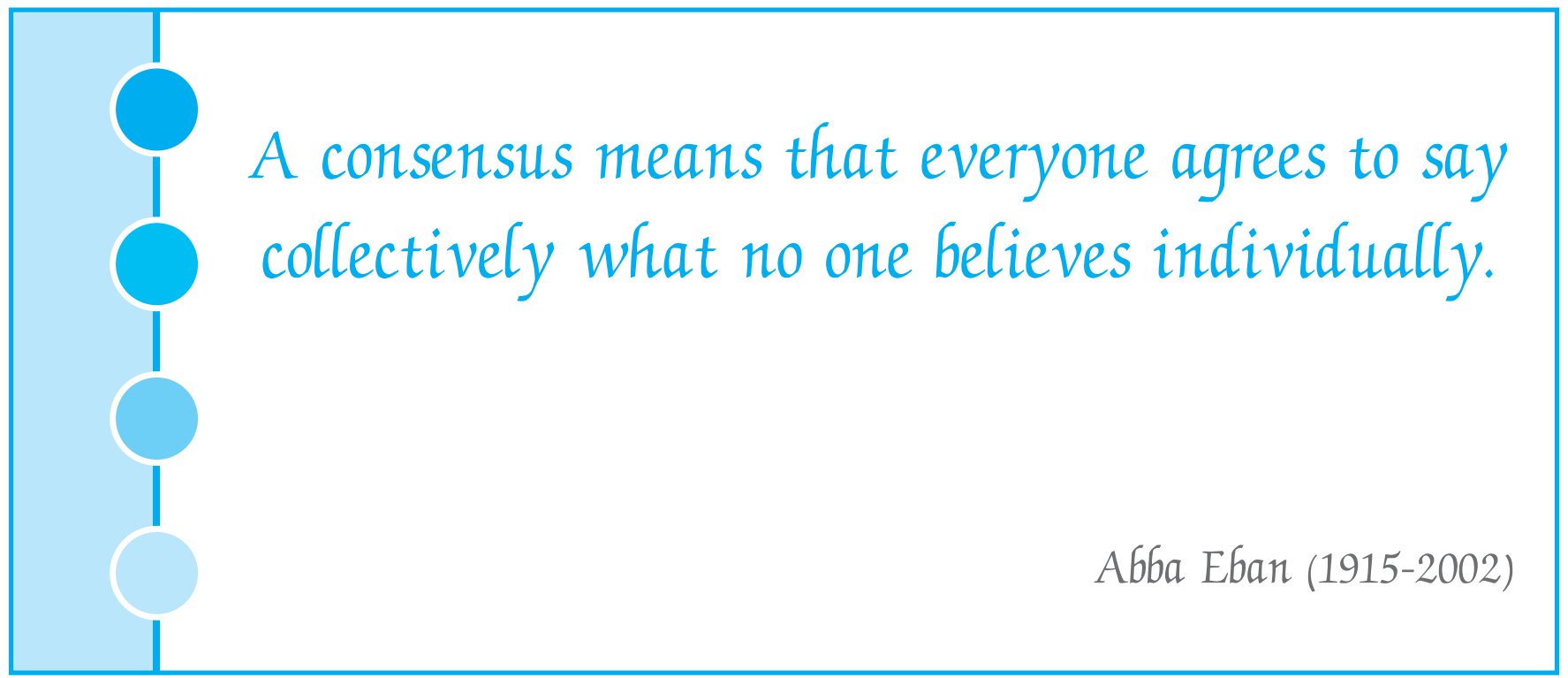

